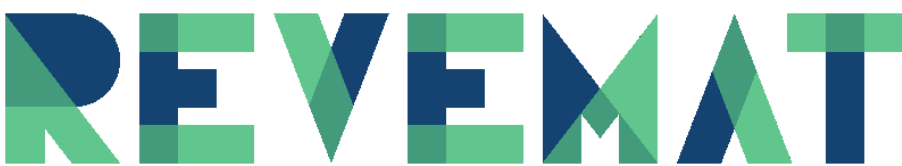

REVISTA ELETRÔNICA DE EDUCAÇÃO MATEMÁTICA

\title{
O CURRÍCULO DE MATEMÁTICA NO ENSINO SUPERIOR: ANÁLISE DAS PRIMEIRAS MATRIZES CURRICULARES DE UMA INSTITUIÇÃO DE ENSINO SUPERIOR NO AGRESTE DE PERNAMBUCO NO DECORRER DE QUATRO DÉCADAS Higher education math curriculum: analysis of the first curricular matrices of a higher education institution in Pernambuco during four decades
}

\author{
Josilene Maria de Lima TORRES \\ Faculdade do Belo Jardim, Matemática, Belo Jardim, PE, Brasil \\ josilenetorres@yahoo.com.br \\ Dhttps://orcid.org/0000-0002-1825-0097 \\ Edelweis José Tavares BARBOSA \\ Universidade Federal de Pernambuco-UFPE \\ edelweisb@yahoo.com.br \\ Dhttps://orcid.org/0000-0001-6032-9367
}

A lista completa com informações dos autores está no final do artigo

\begin{abstract}
RESUMO
Este trabalho, apresenta um recorte de uma pesquisa de dissertação que encontra-se em andamento na Universidade Federal de Pernambuco - UFPE, a qual busca investigar o impacto que a Faculdade do Belo Jardim - FBJ, mantida pela Autarquia Educacional do Belo Jardim - AEB, tem exercido na formação do/a professor/a de Matemática na Educação Básica no agreste pernambucano ao longo de quatro décadas. Para tanto investigaremos as transformações curriculares, formativas e históricas do curso de Licenciatura em Matemática da instituição. A proposta do estudo apresentado neste trabalho é a análise das primeiras matrizes curriculares vivenciadas na instituição nas décadas de 70 e 80 bem como os documentos oficiais norteadores do respectivo período. Na efetivação da pesquisa realizou-se um aprofundamento teórico do tema buscando posicionar o objeto de estudo no conjunto das discussões teóricas que embasaram o estudo em documentos oficiais, livros, artigos, teses e dissertações que tratam da história e breve trajetória da FBJ, do currículo no Curso de Licenciatura em Matemática na Instituição, pareceres do MEC e Conselho Estadual de Educação. O estudo teve como procedimento metodológico a pesquisa explicativa sob a forma documental de caráter qualitativo, na qual foram consultados autores que identificaram em seus estudos e pesquisas a relevância da Licenciatura em Matemática. A análise das matrizes curriculares da instituição permitiu relevantes reflexões das dificuldades superadas para atender as necessidades temporais com relação ao currículo de Matemática e a formação inicial do professor/a de Matemática.
\end{abstract}

Palavras-chave: Currículo, Licenciatura, Matemática, Matriz curricular.

\section{ABSTRACT}

This paper presents a clipping of a dissertation research that is underway at the Federal University of Pernambuco - UFPE, which seeks to investigate the impact that the Belo Jardim College - FBJ, maintained by the Belo Jardim Educational Authority - AEB, has been training the teacher of Mathematics in Basic Education in the Pernambucan forest for four decades. For this we will investigate the curricular, formative and historical transformations of the course of Mathematics Degree in the institution. The purpose of the study presented in this paper is the analysis of the first curricular matrices lived in the institution in the 70 s and 80 s as well as the official documents guide the respective period. In the realization of the research, a theoretical deepening of the theme was carried out seeking to position the object of study in the set of theoretical discussions that supported the study in official documents, books, articles, theses and dissertations that deal 
with the history and brief trajectory of the FBJ, the curriculum. in the Mathematics Degree Course at the Institution, opinions from MEC and State Board of Education. The study had as methodological procedure the explanatory research in the documentary form of qualitative character, in which authors were consulted who identified in their studies and research the relevance of the Degree in Mathematics. The analysis of the curricular matrices of the institution allowed relevant reflections of the difficulties overcome to meet the temporal needs in relation to the Mathematics curriculum and the initial formation of the Mathematics teacher.

Keywords: Curriculum, Graduation, Mathematics, Matrix Curriculum.

\section{INTRODUÇÃO}

A Faculdade do Belo Jardim - FBJ atua na formação acadêmica dos profissionais em educação há quatro décadas oferecendo cursos de licenciatura, entre os quais destacase nesta pesquisa o Curso de Licenciatura em Matemática, como parte do projeto de mestrado em curso na Universidade Federal de Pernambuco - UFPE.

A inquietação para a pesquisa teve início com o cumprimento das atividades acadêmicas para o Curso de Licenciatura em Matemática da Faculdade do Belo Jardim FBJ, ainda no início do primeiro semestre de 2018, realizando-se a Semana Acadêmica de Matemática e para tanto foram convidados profissionais na área de Matemática que não fizessem parte do quadro de profissionais da instituição para participar com palestras, oficinas ou minicursos.

Dentre os convidados praticamente todos eram professores/as egressos/as da instituição sendo profissionais renomados no ensino de Matemática com vínculo efetivo na Universidade Federal de Pernambuco - UFPE, Instituto Federal de Pernambuco - IFPE, Rede Estadual, ente outros, fato que alegrou os/as estudantes e professores/as participantes do evento como ainda trouxe inquietações com relação ao impacto que a FBJ tem exercido na formação inicial destes profissionais e consequentemente na Educação Matemática da região.

A Instituição era a única da região nos anos 70 que oferecia o Ensino Superior, especialmente as Licenciaturas, extremamente necessárias e urgentes naquele período atendendo estudantes de cidades circunvizinhas e estados como Maceió, Bahia, Paraíba, entre outros, somente há aproximadamente dez anos depois teve a criação da Licenciatura em Matemática no Instituto Federal de Pernambuco - IFPE e na Universidade Federal de Pernambuco - UFPE.

Este estudo, teve como foco a análise da dimensão curricular do Curso de Licenciatura em Matemática da FBJ, na formação do/a futuro/a professor/a que ensina 
Matemática, assim, nas discussões e possíveis impactos curriculares dos atuais programas de iniciação à docência na formação dos/as futuros/as professores/as. Desta forma, o objetivo desta investigação foi analisar as primeiras matrizes curriculares nos anos 70 e 80 do Curso de Licenciatura em Matemática da FBJ, que tem formado professores/as de Matemática que atuam na Educação Básica e Ensino Superior, com maior ênfase no agreste pernambucano.

Em nosso país as discussões acerca do processo de formação do professor de Matemática têm-se tornado mais evidentes, conforme aponta Ferreira (2003) a partir da década de 90 houve transformações no paradigma de pesquisa em Educação Matemática, assim, ampliando os estudos sobre a formação do professor de Matemática.

De acordo com Silva (2013, p.18), “a Sociedade Brasileira de Educação Matemática, (SBEM) tem elegido como um de seus principais focos a Formação de Professores de Matemática nos Cursos de Licenciatura", propiciando assim, debates diversos em Encontros Nacionais e Regionais, gerando ainda publicações de livros e artigos sobre o tema.

O desenvolvimento do conhecimento profissional necessário ao exercício da profissão de professor compreende diversos componentes que, embora nos últimos anos tendo vindo a ser descritas de variadas formas, não se distanciam muito do modelo de Shulman (1986), o Conhecimento Pedagógico do Conteúdo, mais conhecido como PCK (Pedagogical Content Knowledge), que considera o conhecimento profissional específico dos professores, conhecimento que é fruto da prática destes em sala de aula ao reformular os conhecimentos obtidos na universidade dialogando prática com a produção de um conhecimento inovador, o PCK. Assim, de acordo com o autor para ensinar Matemática é necessário desenvolver conhecimentos matemáticos e sobre a Matemática, assim como, conhecimento sobre como ensinar, nas suas vertentes mais didática ou mais pedagógica.

No processo de desenvolvimento pessoal do conhecimento profissional estão envolvidas perspectivas e crenças que têm um papel importante não só no modo como o futuro professor aprende, mas também em como virá a usar esse conhecimento, desenvolvido num contexto particular da formação inicial, na sua atividade como professor/a.

A formação de professores/as de Matemática, de acordo com D’Ambrósio (2012, p.80) é "um dos grandes desafios para o futuro" visto que o/a professor/a egresso/a deve saber o que vem a ser Matemática, a constituição da atividade matemática e da sua 
aprendizagem, além do ambiente propicio à aprendizagem matemática. De fato, são pontos relevantes e que podem melhorar o ensino de Matemática atendendo a demanda atual.

O curso de Licenciatura em Matemática vem sendo reconstruído ao longo dos anos com a inserção de novas disciplinas específicas e pedagógicas de acordo com as orientações dos Conselhos Estaduais de Educação, no entanto, mesmo com as novas matrizes curriculares tem se mostrado fragilizado frente à demanda que o/a futuro/a professor/a irá enfrentar na prática pedagógica escolar.

Para a efetivação desta pesquisa, utilizou-se como procedimento metodológico a pesquisa explicativa, que de acordo com Rudio (2002) busca descrever, narrar, explicando as causas, e sob a forma de pesquisa documental, tendo como base, os documentos oficiais, atas, regulamentos, bibliográfica com pesquisa em livros e revistas. A abordagem utilizada é qualitativa, partindo do princípio da reflexão e análise da realidade observada pelo pesquisador, conforme aponta Oliveira (2008), através de técnicas que o facilitem na compreensão do objeto estudado.

Nesta pesquisa buscou-se ter conhecimento de como eram traçadas e delineadas as matrizes curriculares iniciais da instituição nas décadas de 70 e 80 no Curso de Licenciatura em Matemática da FBJ no agreste pernambucano. Com o propósito de responder a esta indagação identificou-se como objetivo geral analisar as transformações ocorridas nas primeiras matrizes curriculares do Curso de Licenciatura em Matemática da FBJ, assim como, historiar brevemente a trajetória da instituição, especialmente com relação ao Curso de Licenciatura em Matemática, por meio de análise dos documentos normatizadores do curso de Licenciatura em Matemática; das suas matrizes curriculares e dos pareceres do Conselho Estadual de Educação.

Através desta investigação, busca-se uma reflexão e compreensão do percurso histórico do Ensino Superior em Matemática, especialmente na FBJ, no processo da formação inicial do/a professor/a de Matemática a partir da matriz curricular.

\section{CONSIDERAÇÕES PARCIAIS SOBRE O PERCURSO HISTÓRICO DA FACULDADE DO BELO JARDIM - FBJ}

A antiga Faculdade de Formação de Professores - FABEJA, hoje denominada, Faculdade do Belo Jardim - FBJ, é uma faculdade pioneira no agreste do Estado de Pernambuco no Ensino Superior, a qual oferece cursos de licenciatura para toda a região 
além de outros Estados. A FBJ, mantida pela Autarquia Educacional do Belo Jardim - AEB, conforme consta na portaria do Ministério de Educação e Cultura $n^{\circ} 159$ de 24 de abril de 1984, Brasil,

tem como missão, produzir e disseminar o conhecimento nos diversos campos do saber, tornando-se centro de excelência na formação de professores e profissionais da educação, comprometida com uma política de formação que visa à preparação de profissionais competentes e atualizados para o exercício da profissional e a melhoria das condições de vida da sociedade; estando comprometida com a pluralidade e a diversidade de saberes construída e possuída pelos agentes envolvidos no processo de construção e reconstrução da aprendizagem.

Com essa filosofia de ensino há quarenta e dois anos a instituição vêm formando professores e professoras os quais em sua maioria atuam no agreste pernambucano, tendo assim, um impacto significativo na formação inicial dos/as egressos/as da instituição.

A FABEJA foi designada pela Lei Municipal $n^{0}$ 121, de 05 de abril de 1971, como resultado da idealização de educadores que ansiavam em ofertar o Ensino Superior no município, buscando suprir a carência de professores/as licenciados/as para atuar na cidade e na região circunvizinha, além de estados próximos, uma luta dos idealizadores para tornar o sonho em realidade, concretizando um antigo sonho de Artur Barbosa Maciel no governo do prefeito Sr. Sebastião Lopes. Foi criada em 26/05/1975, pela Lei Municipal $n^{\circ} 231 / 75$ e autorizada para funcionar com os cursos de Ciências, Estudos Sociais e Letras, em nível de licenciatura Curta ( $\left.1^{\circ} \mathrm{Grau}\right)$ pelo Conselho Estadual de Educação de Pernambuco, através da resolução nº 15/76 de 19/08/1976.

Sendo esta, uma proposta de instituição de direito privado, o Poder Executivo Municipal, em agosto de 1976, publicou a Lei 231/75 transformando a Instituição em Autarquia Educacional, supervisionada pela Prefeitura Municipal de Belo Jardim, passando a ter personalidade jurídica e patrimônio próprios, autonomia financeira, administrativa e didática, com a nomeação do diretor pelo governo municipal mediante lista tríplice apresentada pela congregação de professores com mandato de quatro anos. O Conselho Estadual de Educação concedeu parecer favorável ao seu funcionamento sob o n²04/76, datado de 19/08/1976.

O primeiro vestibular foi realizado em setembro de 1976, sendo oferecidos cursos de Estudos Sociais, Ciências e Letras, havendo 270 inscritos, uma média de 85 alunos por curso. Foram iniciadas as atividades com um quadro de 20 professores, funcionando, inicialmente, no Grupo Escolar José Orlando Leite Cavalcanti, na rua Geminiano Maciel s/n, e posteriormente, em 1978, passando a funcionar no Colégio Industrial, atual Colégio 
Diocesano, havendo a cessão do prédio do Castelinho de propriedade municipal, localizado ao lado do referido colégio, para o funcionamento da Autarquia, algumas salas de aula e a biblioteca.

Em 1980, a direção contratou uma Assessoria Técnica para montagem do processo de reconhecimento, sendo concluído e enviado ao MEC no ano seguinte. Em 24 de abril de 1984, foi publicada a portaria $n^{\circ} 159$ pelo Ministério de Educação e Cultura, reconhecendo os cursos da FABEJA e ratificando-a como uma Instituição de Ensino Superior com a finalidade de formar professores/as, realizar pesquisas e desenvolver atividades que enriqueçam o acervo de conhecimentos e técnicas, contribuir para o progresso cultural do município e da região, e propiciar condições para o aperfeiçoamento e a especialização em nível superior.

Ainda neste mesmo ano foi lançada a pedra fundamental da construção da sede própria pelo executivo municipal, mas posteriormente, foi adquirido um novo terreno no sítio Inhumas, onde atualmente a instituição funciona com sede própria desde 1989. Cabe observar que, em 1984, a Faculdade intensificou seus estudos, visando a plenificação dos Cursos de Licenciatura até então mantidos, sendo solicitado ao presidente do Conselho Estadual de Educação (CEE), a conversão dos cursos de Licenciatura Curta nos seguintes cursos: Biologia, Geografia, História, Letras e Matemática, incluindo o projeto do Regimento aprovado pela Congregação, quadros curriculares e a relação dos docentes em exercício na Instituição.

Em 19/06/1985 através da Portaria n 476, do MEC os cursos da FABEJA, foram transformados em Licenciatura Plena em Ciências com Habilitação em Matemática e Biologia; Licenciatura Plena em Geografia; Licenciatura Plena em História e Licenciatura Plena em Letras com habilitação em Inglês e Português, coroando o esforço do corpo docente e discente e das autoridades estaduais que tanto se empenharam, atendendo aos anseios da comunidade Belojardinense.

Estes cursos foram reconhecidos pelo Conselho Federal de Educação pela Portaria ministerial 1.329 de 05.09.94, sendo que, a Prefeitura Municipal de Belo Jardim a entidade mantenedora, através da Lei Municipal n 383 de 28 de agosto de 1980. A organização administrativa e pedagógica da FABEJA é composta por um Diretor, um Vice- Diretor, pela Congregação e Conselho Departamental e a Administração Financeira é através da AEB Autarquia Educacional de Belo Jardim, órgão diretamente ligado a Prefeitura, composta por um Presidente, um Vice-Presidente e pelo Conselho Fiscal. 
A partir desse momento, aumentou a procura por vagas na FABEJA, tanto para início quanto para pagamento de disciplinas avulsas para efeito de conclusão da Plena, sendo oferecidas 210 (duzentas e dez) vagas, no ano de 1986, havendo 807 (oitocentos e sete) inscritos, além da oferta de 210 (duzentas e dez) vagas de complementação para Biologia, História e Letras. Atualmente, a instituição conta com cursos de graduação, pós-graduação Lato Sensu, bem como, cursos de extensão.

\section{CONSIDERAÇÕES PARCIAIS DAS NORMATIZAÇÕES OFICIAIS PARA A FORMAÇÃO INICIAL DOIA PROFESSOR/A DE MATEMÁTICA}

Entende-se que, a formação inicial dos/as professores/as de acordo com Imbernón (2011), fornece embasamentos para a construção do conhecimento pedagógico especializado e deve proporcionar ao/a professor/a um conjunto de conhecimentos e experiências nas áreas científica, cultural, contextual, psicopedagógico e pessoal, de modo a contribuir para que o/a professor/a sinta-se preparado para enfrentar a complexidade do sistema educativo. Para Tardif (2010), a formação inicial visa habituar os/as estudantes, futuros/as professores/as, à prática profissional dos/as professores/as de profissão e fazer deles práticos e reflexivos. Os dois autores reforçam a ideia de que a formação inicial é a base para que o/a futuro/a professor/a possa aprender e construir técnicas que o auxiliem no oficio do magistério.

Para que este profissional possa desempenhar um bom exercício em sua prática educativa é necessário compreender o currículo, que na concepção de Sacristán (2000), é essencial para o exercício do magistério, visto ser um ponto de referência que mesmo de forma paradigmática, permite a apreciação das relações entre as orientações teóricas e realidade prática, os modelos ideais de escola e a escola possível. Este mesmo autor nos auxilia na compreensão de que o currículo não se trata somente de um documento enrijecido, mas de um todo complexo, envolvendo distintos atores e extratos sociais, sendo produto de constante (re)construção definidas a partir das diversas instancias que se apresentam a ele.

Corroborando com estas concepções, Pacheco (2005) considera o currículo como um programa de ensino que determina distintos conteúdos, um projeto educacional que objetiva a formação crítico-emancipadora dos sujeitos nele inseridos. 
Nos anos 70 a 80 as teorias curriculares tecnicistas/ behavoristas eram aceitas pela facilidade na excução das tarefas, como um manual de instruções. Na década de 90 houve um movimento chamado de Nova Sociologia de Educação, tendo como líder o sociólogo Michael Young, elegendo o currículo como responsável pela produção das desigualdades sociais reforçando a ideia da sua não neutralidade.

Neste sentido, destacam-se teóricos e estudiosos como William Pinar, com suas obras Understanding Curriculum (1995) e O que é a Teoria de Curriculo? (2007), que influenciou no reconhecimento da dimensão social da educação escolar e o papel dos professores; ainda Henry Giroux que revolucionou as ideias anteriores com o pensamento de que o ensino não é técnico nem neutro escrevendo diversos livros que reforçam sua hipótese na teorias de orientação sociocrítica e cultural. Michael Apple (ano) reforçou a ideia de que a escola não é simplesmente transmissora de conhecimento, devendo levar em conta a heterogeneidade cultural da sociedade.

Nesta perspectiva, destaca-se às teorias pós-críticas do currículo as contribuições e aprofundamentos dos estudos sob a perspectiva de Lopes (2014) que descreveu a contribuição de vários estudiosos no assunto. Com relação ao currículo em Matemática os estudos de Godoy (2016) analisam o papel das disciplinas escolares a partir das questões da contemporaneidade, entendendo a Matemática como prática social, cultural e política, e defendendo um ensino mais igualitário.

Para que o professor/a egresso/a tenha condições mínimas de preparo acadêmico e consiga exercer seu oficio com tranquilidade o Ministério da Educação e Cultura - MEC, estabelece as diretrizes curriculares, pareceres e leis a partir de documentos oficiais que norteiam as atividades acadêmicas, como a matriz curricular que será efetivada nas universidades, sendo imprescindíveis para uma formação de qualidade.

Os cursos de licenciatura foram criados na década de 1930, numa época que eram tidos como uma parte "menos nobre" das universidades, conforme aponta Junqueira e Manrique (2015), somente dezoito anos depois a Lei 5.540/68 definida como Reforma Universitária traz encaminhamentos para melhorar o Ensino Superior. A Lei 5.692, em 1971, trouxe novas orientações sendo substituída pela Lei 9.394/96, que estabeleceu como um dos deveres das universidades a definição dos currículos de seus cursos e programas, de acordo com as diretrizes gerais pertinentes, permitindo assim que a avaliação da Educação Superior ficasse em evidência entre as políticas educacionais, tanto norteando as diretrizes do MEC, como orientando suas ações concretas. 
As Diretrizes Curriculares Nacionais para os Cursos de Licenciatura em Matemática, orientam que, o/a professor/a egresso/a de um curso de licenciatura precisa apresentar uma apropriada preparação para sua carreira e de forma que a Matemática seja usada essencialmente como um processo contínuo de aprendizagem, bem como, uma formação pedagógica que esteja voltada para a prática, possibilitando a vivência crítica da realidade e uma formação geral complementar abrangendo outros campos do conhecimento, os quais são imprescindíveis ao exercício do magistério.

De acordo com Garcia (2003, p. 64, apud Ludwig, 2007, p. 3),

Os profissionais formados nos cursos de Matemática devem ter uma visão abrangente do papel social do educador na sociedade; capacidade de compreender, criticar e utilizar novas ideias e tecnologias; participar de programas de formação continuada e trabalhar em equipes multidisciplinares; capacidade de comunicar-se matematicamente e compreender Matemática, de estabelecer relações com outras áreas do conhecimento, de expressar-se com clareza, precisão e objetividade.

Neste contexto, percebe-se a necessidade de formar professores/as que sejam capazes de refletir sobre sua prática educativa, possibilitando seu crescimento intelectual, condição fundamental para as transformações que se fazem necessárias na Educação, além da atualização profissional com sua área e ainda com outras áreas do conhecimento.

O Parecer CNE/CES 1.302/2001 enfatiza que "os cursos de Licenciatura em Matemática trazem como objetivo principal a formação de professores/as para atuar na Educação Básica" o que reforça a ideia de que o curso visa formar professores que atuem no Ensino Fundamental e Médio, destacando que o professor deve ter como características, a concepção de que exerce um papel social, sendo sensível à interpretação das ações dos alunos/as, compreender que a Matemática está atrelada ao exercício da cidadania e que o "conhecimento matemático pode e deve ser acessível a todos", tendo ainda a consciência "de seu papel na superação dos preconceitos, traduzidos pela angústia, inércia ou rejeição" fato corriqueiro no exercício do ensino e aprendizagem.

Assim, o/a professor/a deve exercer seu papel no magistério, tendo consciência de que ser professor exige além de ensinar os conteúdos específicos da disciplina, a compreensão do contexto social na sociedade escolar, podendo inclusive modificar a realidade local.

De acordo com Gatti e Nunes (2008), em decorrência do Parecer CNE/CP 009/2001, são considerados essenciais para o desenvolvimento dos cursos de Licenciatura, as competências indispensáveis para à ação do professor, como ainda a proposta pedagógica, 
especialmente do currículo e da avaliação, quanto da organização institucional e da gestão da escola de formação.

\section{CONSIDERAÇÕES PARCIAIS DAS MATRIZES CURRICULARES DA FBJ NAS DÉCADAS DE 70 A 80}

A formação inicial de professores oferecida pela Faculdade do Belo Jardim na década de 70 era dos cursos de Licenciatura Curta assegurada pela lei 5.692/71visto a necessidade de uma formação de professores mais rápida, a qual constava de uma carga horária menor, com apenas cinco períodos, o professor formado nesta modalidade poderia dar aulas ao Ensino Primário apenas, que hoje chamamos de Ensino Fundamental.

$\mathrm{Na}$ tabela 1 a seguir podemos examinar a matriz curricular da Licenciatura Curta oferecida pela então FABEJA entre os anos de 1976 a 1980. Neste documento, verifica- se que a modalidade de ensino seria cumprida em apenas cinco períodos em apenas dois anos e meio, fato que confirma a ideia de uma formação rápida para atender uma demanda cada vez maior e necessitada de conhecimentos.

Tabela 1: Matriz Curricular da FABEJA do Curso de Licenciatura Curta

\section{Matriz Curricular}

Curso: Ciências - Licenciatura Curta 1976 a 1980

Currículo: 1976

Reconhecido pela Portaria Ministerial no 159 de 17/04/1984 - D.O.U. 24/04/1984

Reconhecido pela Portaria Ministerial n 159 de 17/04/1984 - D.O.U. 24/04/1984

\begin{tabular}{|c|c|c|c|}
\hline Período & Disciplina & C. $\mathrm{H}$. & Créditos \\
\hline $1^{\circ}$ & BIOLOGIA I & 60 & 4 \\
\hline $1^{\circ}$ & DESENHO I & 60 & 4 \\
\hline $1^{\circ}$ & ESTUDOS BRASILEIROS I & 30 & 2 \\
\hline $1^{\circ}$ & FÍSICA I & 60 & 4 \\
\hline $1^{\circ}$ & MATEMÁTICA I & 60 & 4 \\
\hline $1^{\circ}$ & PORTUGUÊS & 60 & 4 \\
\hline \multirow[t]{2}{*}{$1^{\circ}$} & QUÍMICA I & 60 & 4 \\
\hline & Total $1^{\circ}$ Período: & 390 & 26 \\
\hline $2^{\circ}$ & SOCIOLOGIA & 60 & 4 \\
\hline $2^{\circ}$ & BIOLOGIA II & 60 & 4 \\
\hline $2^{\circ}$ & DESENHO II & 60 & 4 \\
\hline $2^{\circ}$ & ESTUDOS BRASILEIROS II & 30 & 2 \\
\hline $2^{\circ}$ & FÍSICA II & 60 & 4 \\
\hline $2^{\circ}$ & MATEMÁTICA II & 60 & 4 \\
\hline \multirow[t]{2}{*}{$2^{\circ}$} & QUÍMICA II & 60 & 4 \\
\hline & Total $2^{\circ}$ Período: & 390 & 26 \\
\hline $3^{\circ}$ & BIOLOGIA III & 60 & 4 \\
\hline $3^{\circ}$ & BOTÂNICA & 60 & 4 \\
\hline
\end{tabular}




\begin{tabular}{|c|c|c|c|}
\hline $3^{\circ}$ & FÍSICA III & 60 & 4 \\
\hline $3^{\circ}$ & INTRODUÇÃO À FILOSOFIA & 60 & 4 \\
\hline $3^{\circ}$ & MATEMÁTICA III & 60 & 4 \\
\hline \multirow[t]{2}{*}{$3^{\circ}$} & QUÍMICA III & 60 & 4 \\
\hline & Total $3^{\circ}$ Período: & 360 & 24 \\
\hline $4^{\circ}$ & DIDÁTICA & 60 & 4 \\
\hline $4^{\circ}$ & $\begin{array}{l}\text { ESTRUTURA E FUNCIONAMENTO DO } \\
\text { ENSINO DE } 1^{\circ} \mathrm{GRAU}\end{array}$ & 60 & 4 \\
\hline $4^{\circ}$ & FÍSICA IV & 60 & 4 \\
\hline $4^{\circ}$ & MATEMÁTICA IV & 60 & 4 \\
\hline $4^{\circ}$ & PSICOLOGIA EDUCACIONAL I & 60 & 4 \\
\hline \multirow[t]{2}{*}{$4^{\circ}$} & QUÍMICA IV & 60 & 4 \\
\hline & Total $4^{\circ}$ Período: & 360 & 24 \\
\hline $5^{\circ}$ & PRÁTICA DE ENSINO (CIÊNCIAS) & 90 & 6 \\
\hline $5^{\circ}$ & GEOLOGIA & 60 & 4 \\
\hline $5^{\circ}$ & MATEMÁTICA V & 60 & 4 \\
\hline $5^{\circ}$ & PSICOLOGIA EDUCACIONAL II & 60 & 4 \\
\hline $5^{\circ}$ & ZOOLOGIA & 60 & 4 \\
\hline \multirow[t]{3}{*}{$5^{\circ}$} & PRÁTICA DE ENSINO (MATEMÁTICA) & 90 & 6 \\
\hline & Total $5^{\circ}$ Período: & 420 & 28 \\
\hline & Total do Curso: & 1920 & 128 \\
\hline
\end{tabular}

Fonte: Pesquisa, 2019.

A partir da Matriz Curricular, pode-se observar que o licenciando neste período estudava disciplinas voltadas a Ciências Naturais e Exatas, fato que, torna compreensível a antiga ideia que se tinha de que o professor de Matemática poderia ensinar biologia, química, física, embora que o aprendizado fosse extremamente curto e com pouquíssimas horas/aula em cada disciplina ofertada na matriz curricular.

No entanto, modelo sanava a necessidade da época de formar professores/as para atuação imediata e rápida na Educação Básica, conforme estabelecia a Lei 5.692/71, que a princípio foi autorizada para a FABEJA. Para ter direito a ensinar no Ensino Médio os/as professores/as realizavam a complementação curricular, como podemos verificar na tabela 2 a seguir contendo mais de três períodos divididos em um ano e meio que permitiam um estudo mais aprofundado e sistematizado.

Tabela 2: Matriz Curricular da FABEJA do Curso de Licenciatura para complementação da Licenciatura Plena.

\section{Matriz Curricular}

Curso: CIÊNCIAS HAB. MATEMÁTICA - COMPLMENTAÇÃO Currículo: MATC - 1985 PORTARIA MEC Nº 476 em 19/06/1985

\begin{tabular}{clcc} 
Período & \multicolumn{1}{c}{ Disciplina } & C. H. & Créditos \\
$6^{\circ}$ & CÁLCULO DIFERENCIAL E INTEGRAL I & 90 & 6 \\
$6^{\circ}$ & LÍNGUA PORTUGUESA II & 60 & 4 \\
$6^{\circ}$ & FÍSICO-QUÍMICA & 60 & 4 \\
$6^{\circ}$ & ELEMENTOS DE GEOLOGIA & 60 & 4 \\
\hline
\end{tabular}




\begin{tabular}{|c|c|c|c|}
\hline $6^{\circ}$ & QUIIMICA ORGÂNICA & 60 & 4 \\
\hline $6^{\circ}$ & ESTRUTURA E FUNCIONAMENTO DO ENSINO DE $1^{\circ} \mathrm{E} 2^{\circ} \mathrm{GRAU}$ & 60 & 4 \\
\hline $6^{\circ}$ & CÁLCULO DIFERENCIAL E INTEGRAL II (CURSO DE FÉRIAS) & 90 & 6 \\
\hline \multirow[t]{2}{*}{$6^{\circ}$} & METODOLOGIA CIENTIIFICA (CURSO DE FÉRIAS) & 60 & 4 \\
\hline & Total $6^{\circ}$ Período: & 540 & 36 \\
\hline $7^{\circ}$ & CÁLCULO DIFERENCIAL E ITGRAL III & 90 & 6 \\
\hline $7^{0}$ & ECOLOGIA GERAL & 60 & 4 \\
\hline $7^{\circ}$ & QUÍMICA ORGÂNICA & 60 & 4 \\
\hline $7^{0}$ & PRÁTICA DE ENSINO DE $1^{\circ} \mathrm{E} 2^{\circ} \mathrm{GRAUS}$ & 90 & 6 \\
\hline $7^{\circ}$ & ÁLGEBRA LINEAR & 60 & 4 \\
\hline $7^{0}$ & ÁLGEBRA I & 60 & 4 \\
\hline $7^{\circ}$ & ESTATÍSTICA (CURSO DE FÉRIAS) & 60 & 4 \\
\hline \multirow[t]{2}{*}{$7^{\circ}$} & ANÁLISE REAL (CURSO DE FÉRIAS) & 60 & 4 \\
\hline & Total $7^{\circ}$ Período: & 540 & 36 \\
\hline $8^{\circ}$ & CÁLCULO DIFERENCIAL E INTEGRAL IV & 60 & 4 \\
\hline $8^{\circ}$ & CÁLCULO DAS PROBABILIDADES & 60 & 4 \\
\hline $8^{\circ}$ & ÁLGEBRA LINEAR II & 60 & 4 \\
\hline $8^{\circ}$ & GEOMETRIA PLANA & 60 & 4 \\
\hline $8^{\circ}$ & ÁLGEBRA II & 60 & 4 \\
\hline $8^{\circ}$ & CÁLCULO NUMÉRICO & 60 & 4 \\
\hline $8^{\circ}$ & ANÁLISE REAL II (CURSO DE FÉRIAS) & 60 & 4 \\
\hline \multirow[t]{3}{*}{$8^{\circ}$} & EQUAÇÕES DIFERENCIAIS & 60 & 4 \\
\hline & Total $8^{\circ}$ Período: & 480 & 32 \\
\hline & Total do Curso: & 1560 & 104 \\
\hline
\end{tabular}

Fonte: Pesquisa, 2019.

Observando a matriz curricular de complementação da Licenciatura em Matemática percebemos que embora traga disciplinas em sua maioria específicas ainda traz outras disciplinas que pouco essenciais ao ensino de Matemática e inclusive atualmente não são ofertadas como Físico-Química, Elementos de Geologia, Química Orgânica, Ecologia Geral. Mesmo com estes problemas, o Curso significava tanto a oportunidade de emprego como a consolidação deste, no caso dos professores/as que não tinham a habilitação mínima necessária para o cargo que se propunham. Alguns egressos/as do Curso de Licenciatura Curta precisaram realizar a complementação em outras instituições, inclusive em alguns casos, optavam pela complementação em Matemática e em Biologia. Com o reconhecimento do MEC, portaria $n^{\circ} 476 / 85$, a FABEJA pode ofertar a complementação e consequentemente a Licenciatura Plena.

Tabela 3: Grade Curricular da FABEJA do Curso de Licenciatura Plena em Matemática

\section{Grade Curricular}

Curso: CIÊNCIAS - HABILITAÇÃO EM MATEMÁTICA Currículo: CIE-M - 1985.1

Parecer CEE/PE N 27/1985-CES em 27/02/1985

Reconhecido pela Portaria Ministerial no 1.329 de 05/09/1994 - D.O.U. 06/09/1994

\begin{tabular}{clcc} 
Período & \multicolumn{1}{c}{ Disciplina } & C. H. & Créditos \\
$1^{\circ}$ & ESTUDOS DOS PROBLEMAS BRASILEIROS & 30 & 2 \\
$1^{\circ}$ & LÍNGUA PORTUGUESA I & 60 & 4
\end{tabular}




\begin{tabular}{|c|c|c|c|}
\hline $1^{\circ}$ & MATEMÁTICA BÁSICA & 90 & 6 \\
\hline $1^{\circ}$ & METODOLOGIA CIENTÍFICA & 60 & 4 \\
\hline $1^{\circ}$ & QUÍMICA GERAL & 60 & 4 \\
\hline \multirow[t]{2}{*}{$1^{\circ}$} & SOCIOLOGIA & 60 & 4 \\
\hline & Total $1^{\circ}$ Período: & 360 & 24 \\
\hline $2^{\circ}$ & CÁLCULO DIFERENCIAL E INTEGRAL I & 90 & 6 \\
\hline $2^{\circ}$ & ESTUDOS DOS PROBLEMAS BRASILEIROS & 30 & 2 \\
\hline $2^{\circ}$ & FILOSOFIA & 60 & 4 \\
\hline $2^{\circ}$ & FÍSICA GERAL I & 60 & 4 \\
\hline $2^{\circ}$ & LÍNGUA PORTUGUESA II & 60 & 4 \\
\hline \multirow[t]{2}{*}{$2^{\circ}$} & QUÍMICA ORGÂNICA & 60 & 4 \\
\hline & Total $2^{\circ}$ Período: & 360 & 24 \\
\hline $3^{\circ}$ & BIOLOGIA GERAL & 90 & 6 \\
\hline $3^{\circ}$ & CÁLCULO DIFERENCIAL E INTEGRAL II & 90 & 6 \\
\hline $3^{\circ}$ & ELEMENTOS DE GEOLOGIA & 60 & 4 \\
\hline $3^{\circ}$ & FÍSICA GERAL II & 60 & 4 \\
\hline \multirow[t]{2}{*}{$3^{\circ}$} & PRÁTICA DE EDUCAÇÃO FÍSICA & 30 & 2 \\
\hline & Total $3^{\circ}$ Período: & 330 & 22 \\
\hline $4^{\circ}$ & CÁLCULO DAS PROBABILIDADES & 60 & 4 \\
\hline $4^{\circ}$ & CÁLCULO DIFERENCIAL E INTEGRAL III & 90 & 6 \\
\hline $4^{\circ}$ & FÍSICA MODERNA & 60 & 4 \\
\hline $4^{\circ}$ & QUÍMICA ORGÂNICA & 60 & 4 \\
\hline \multirow[t]{2}{*}{$4^{\circ}$} & ZOOLOGIA GERAL & 90 & 6 \\
\hline & Total $4^{\circ}$ Período: & 360 & 24 \\
\hline $5^{\circ}$ & BOTANICA GERAL & 90 & 6 \\
\hline $5^{\circ}$ & CÁLCULO DIFERENCIAL E INTEGRAL IV & 90 & 6 \\
\hline $5^{\circ}$ & ECOLOGIA GERAL & 60 & 4 \\
\hline $5^{\circ}$ & ESTATÍSTICA & 60 & 4 \\
\hline \multirow[t]{2}{*}{$5^{\circ}$} & PSICOLOGIA DA EDUCAÇÃO I & 60 & 4 \\
\hline & Total $5^{\circ}$ Período: & 360 & 24 \\
\hline $6^{\circ}$ & ÁLGEBRA LINEAR I & 60 & 4 \\
\hline $6^{\circ}$ & ANÁLISE REAL I & 60 & 4 \\
\hline $6^{\circ}$ & DESENHO GEOMÉTRICO & 90 & 6 \\
\hline $6^{\circ}$ & GEOMETRIA PLANA & 90 & 6 \\
\hline \multirow[t]{2}{*}{$6^{\circ}$} & PSICOLOGIA DA EDUCAÇÃO II & 60 & 4 \\
\hline & Total $6^{\circ}$ Período: & 360 & 24 \\
\hline $7^{\circ}$ & ÁLGEBRA I & 60 & 4 \\
\hline $7^{\circ}$ & ÁLGEBRA LINEAR II & 60 & 4 \\
\hline $7^{\circ}$ & ANÁLISE REAL II & 60 & 4 \\
\hline $7^{\circ}$ & DIDÁTICA & 75 & 5 \\
\hline $7^{\circ}$ & $\begin{array}{l}\text { ESTRUTURA E FUNCIONAMENTO DO ENSINO DE } \\
1^{\circ} \mathrm{E} 2^{\circ} \mathrm{GRAU}\end{array}$ & 60 & 4 \\
\hline \multirow[t]{2}{*}{$7^{\circ}$} & MATEMÁTICA APLICADA I & 60 & 4 \\
\hline & Total $7^{\circ}$ Período: & 375 & 25 \\
\hline $8^{\circ}$ & ÁLGEBRA II & 60 & 4 \\
\hline $8^{\circ}$ & CÁLCULO NUMÉRICO & 60 & 4 \\
\hline $8^{\circ}$ & EQUAÇÕES DIFERENCIAIS & 60 & 4 \\
\hline $8^{\circ}$ & MATEMÁTICA APLICADA II & 60 & 4 \\
\hline \multirow[t]{3}{*}{$8^{\circ}$} & PRÁTICA DE ENSINO $1^{\circ} \mathrm{E} 2^{\circ}$ GRAUS & 150 & 10 \\
\hline & Total $8^{\circ}$ Período: & 390 & 26 \\
\hline & Total do Curso: & 2.895 & 193 \\
\hline
\end{tabular}

Fonte: Pesquisa, 2019. 
A primeira matriz curricular do Curso de Licenciatura Plena em Matemática da FABEJA se confirmou através do Parecer do Conselho Estadual de Educação CEE/PE n ${ }^{\circ}$ 27/1985, trazendo a nomenclatura de Licenciatura em Ciências com habilitação em Matemática, fato que se percebe na matriz curricular acima, na qual oferta disciplinas voltadas ao ensino de Ciências (Física, Química, Biologia) e de Matemática.

Na década de 90, com a Lei de Diretrizes e Bases (Lei n 9.394/96) a Licenciatura Curta não seria permitida "Art. $1^{\circ}$ Os cursos de licenciatura de curta duração previstos na Lei $n^{\circ} 5.692$, de 1971, estão extintos pela Lei $n^{\circ} 9.394$, de 1996, assegurados os direitos dos alunos.". A partir de então, os cursos para formação de professores deveriam ser na modalidade de Licenciatura Plena que exige uma carga horária maior, estabelecendo que as universidades deveriam fixar os currículos dos seus cursos e programas de acordo com as diretrizes gerais. Assim, o licenciado teria mais tempo de preparo, estudo e pesquisa na área, podendo dar aula inclusive no Ensino Médio.

\section{CONSIDERAÇÕES FINAIS}

Neste trabalho, buscamos examinar o delineamento das matrizes curriculares iniciais da instituição delimitando as décadas de 70 e 80 do Curso de Licenciatura em Matemática, da primeira faculdade do agreste pernambucano, a Faculdade do Belo Jardim, em conformidade com as exigências dos documentos oficiais observando as transformações ocorridas no respectivo período.

A trajetória histórica da FBJ, demostra os desafios enfrentados e superados numa época em que existia uma carência significativa em torno da formação de professores/as, a instituição proporcionou a realização de sonhos, a oportunidade de emprego, além de efetivar um ensino de qualidade no município, região e inclusive estados circunvizinhos.

Os documentos e normativas oficiais analisadas demonstram que, as matrizes curriculares propostas são acatadas e efetivadas na instituição além da evolução com o passar dos anos em conformidade temporal. Desta maneira, no início a necessidade por uma formação rápida era atendida com a Licenciatura Curta propiciando posteriormente a sua complementação.

A instituição encontra-se comprometida com a formação de professores/as criando condições favoráveis para que o currículo seja desenvolvido plenamente, viso que, os 
cursos de formação de professores/as têm como missão a promoção de atividades que instiguem nos/as licenciandos/as a análise crítica da atividade docente aliando a teoria com a prática pedagógica escolar, possibilitando a troca de experiências.

$\mathrm{Na}$ disciplina de Matemática, especialmente para o/a professor/a egresso/a de Matemática é primordial uma preparação adequada para sua carreira com uma formação pedagógica voltada para a sua prática, possibilitando a vivência crítica da realidade e ainda, envolvendo outros campos do conhecimento, indispensáveis ao exercício do magistério.

Os estudos curriculares norteiam a ação docente no sentido de significar e dar sentido ao currículo como movimento de ensino e aprendizagem em constante transformação. Assim, julgou-se pertinente analisar as matrizes curriculares que norteiam o Cuso de Licenciatura em Matemática na FBJ afim de, aprofundar o estudo, além de investigar as inquietações levantadas nesta pesquisa, com relação à avaliação de um currículo eficaz e primordial para o trabalho do/a futuro/a professor/a.

Acredita-se que, a partir deste estudo será possível investigar o impacto que a FBJ vem exercendo na Educação Matemática do agreste pernambucano, a partir da sua dimensão curricular e formativa, bem como, a identidade profissional do/a futuro/a professor/a de Matemática, tendo como base a sua formação inicial.

\section{REFERÊNCIAS}

D’AMBRoSIO, U., (2012) Educação matemática: Da teoria à prática, 23ª Ed. - Campinas, SP: Papirus.

FERREIRA, A C. (2003) Um olhar retrospectivo sobre a pesquisa brasileira em formação de professores de matemática. In: FIORENTINI, D (org.) Formação de Professores de Matemática. Campinas, SP: Mercado de Letras.

GARCIA, V. C. (2003) Pensando formas concretas para a prática docente no currículo dos cursos de licenciatura em Matemática. Educação Matemática em Revista - RS. OsórioRS, n.5, p. 64-67.

GATTI, B. A; NUNES, M. M. R. (Coord.). (2008) Formação de professores para o ensino fundamental: instituições formadoras e seus currículos. Relatório final: estudo dos cursos de licenciatura no Brasil: letras, matemática e ciências biológicas. São Paulo: Fundação Carlos Chagas. v. 2. 2 Disponível em: <http://www.fvc.org.br/pdf/Formacao\%20de\%20Professores\%20no\%20Brasil.pdf>. Acesso em: 13 maio 2018.

GODOY, E. V. (2016) Currículo, Cultura e Educação Matemática: uma aproximação possível? Campinas - SP, Papirus. 
IMBERNÓN, F. (2011) Formação docente e profissional: formar-se para a mudança e a incerteza. 9. ed. São Paulo: Cortez.

JUNQUEIRA, S. M. S.; MANRIQUE, A. L. (2015) Reformas curriculares em cursos de licenciatura de Matemática: intenções necessárias e insuficientes. Ciênc. Educ., Bauru, SP, v. 21, n. 3, p. 623-635.

Lei MEC no 9394 de 20 de dezembro de 1996. Lei de Diretrizes e Bases da Educação Nacional. Brasília, DF. Recuperado de http://www.planalto.gov.br/ccivil 03/Leis/L9394.htm

LOPES, A. C.; Macedo, E. (2014). The curriculum field in Brazil since the 1990's. In: William Pinar. (Org.). International Handbook of curriculum Studies-2nd. 1ed.New York: Routledge v. 1, p. 86-100

OLIVEIRA, A. A. (2008) Metodologia da pesquisa - guia prático para apresentação de trabalhos acadêmicos. Florianópolis: Visual Books.

PACHECO, J. A. (2005) Escritos Curriculares. São Paulo: Cortez.

Portaria MEC no 159 de 24 de abril de 1984. Dispõe sobre o reconhecimento dos cursos da FABEJA. Brasília, DF.

RUDIO, F. V. (2002) Introdução ao projeto de pesquisa científica. 30. Ed. Petrópolis: Vozes.

SACRISTÁN, J.G. (2000) O Currículo: uma reflexão sobre a prática. Porto Alegre: ArtMed.

SHULMAN, L. (1986) Knowledge and teaching: Foundations of the new reform. Harvard Educational Review.

SILVA, R. D. (2013) A formação do professor de matemática: um estudo das representações sociais. Campina Grande: EDUEPB.

TARDIF, M. (2010) Saberes Docentes e formação profissional. 11ª ed. Petrópolis: Vozes. 


\section{NOTAS}

\section{TÍTULO DA OBRA}

O currículo de matemática no ensino superior: análise das primeiras matrizes curriculares de uma instituição de ensino superior no agreste de Pernambuco no decorrer de quatro décadas

Josilene Maria de Lima Torres

Especialista em Matemática

Faculdade do Belo Jardim, Matemática, Belo Jardim, PE, Brasil

josilenetorres@yahoo.com.br

Dhttps://orcid.org/0000-0002-1825-0097

\section{Edelweis José Tavares Barbosa}

Docente na Universidade Federal de Pernambuco-UFPE

Programa de Pós-graduação em Ciências e Matemática- UFPE/CAA

edelweisb@yahoo.com.br

Dhttps://orcid.org/0000-0001-6032-9367

\section{Endereço de correspondência do principal autor}

Rua Ceci Leite Cavalcante de Souza, n² 211, CEP: 55157-030, Belo Jardim, PE, Brasil.

\section{AGRADECIMENTOS}

Ao orientador Edelweis Tavares que desde o início incentivou a realização da pesquisa. A secretária da AEB lara Silva que prontamente cedeu os documentos necessários para coleta de dados. Ao presidente da AEB Sebastião Filho que sempre tem apoiado a pesquisa na instituição. Ao professor Marcos Barros da disciplina de Divulgação Científica no mestrado UFPE-CAA. Ao meu esposo Walter e filhos Walter Henrique, Hugo Vinícius e Victor que me auxiliam e fortalecem nos momentos difíceis. Aos meus pais que desde cedo me proporcionaram um olhar diferenciado para a educação. Aos meus familiares pelo carinho e compreensão. Aos colegas e amigos pelas contribuições mesmo que sutis. A todos que compõem a UFPE e FBJ.

\section{CONTRIBUIÇÃO DE AUTORIA}

Concepção e elaboração do manuscrito: J. M. L. Torres, E. J. T. Barbosa

Coleta de dados: J. M. L. Torres

Análise de dados: J. M. L. Torres

Discussão dos resultados: J. M. L. Torres

Revisão e aprovação: E. J. T. Barbosa

\section{CONJUNTO DE DADOS DE PESQUISA}

Todo o conjunto de dados que dá suporte aos resultados deste estudo foi publicado no próprio artigo.

\section{FINANCIAMENTO}

Não se aplica.

\section{CONSENTIMENTO DE USO DE IMAGEM}

Não se aplica.

\section{APROVAÇÃO DE COMITÊ DE ÉTICA EM PESQUISA \\ Não se aplica.}

\section{LICENÇA DE USO}

Os autores cedem à Revemat os direitos exclusivos de primeira publicação, com o trabalho simultaneamente licenciado sob a Licença Creative Commons Attribution (CC BY) 4.0 International. Estra licença permite que terceiros remixem, adaptem e criem a partir do trabalho publicado, atribuindo o devido crédito de autoria e publicação inicial neste periódico. Os autores têm autorização para assumir contratos adicionais separadamente, para distribuição não exclusiva da versão do trabalho publicada neste periódico (ex.: publicar em repositório institucional, em site pessoal, publicar uma tradução, ou como capítulo de livro), com reconhecimento de autoria e publicação inicial neste periódico.

\section{PUBLISHER}

Universidade Federal de Santa Catarina. Grupo de Pesquisa em Epistemologia e Ensino de Matemática (GPEEM). Publicação no Portal de Periódicos UFSC. As ideias expressadas neste artigo são de responsabilidade de seus autores, não representando, necessariamente, a opinião dos editores ou da universidade.

\section{EDITOR}

Méricles Thadeu Moretti e Rosilene Beatriz Machado

EDITOR DA EDIÇÃO ESPECIAL

Claudia Lisete Oliveira Groenwald

HISTÓRICO - uso exclusivo da revista

Recebido em: 01-10-2019 - Aprovado em: 24-11-2019 